\title{
Temperament and character profiles of patients with chronic idiopathic urticaria
}

\author{
Sevil Alan¹, Fatih Canan², Ayşe Akman Karakaş, Nihal Geçici ${ }^{3}$ \\ 'Department of Dermatology and Venereology, Akdeniz University, Antalya, Turkey \\ Head of the Department: Erkan Alpsoy \\ 2Department of Psychiatry, Akdeniz University, Antalya, Turkey \\ Head of the Department: Taha Karaman \\ 3Department of Internal Medicine, Antalya Ataturk State Hospital, Antalya, Turkey \\ Head of the Department: Abdullah Erbil Dırağ
}

Postep Derm Alergol 2015; XXXII (3): 167-172

DOI: $10.5114 /$ pdia.2015.48063

\begin{abstract}
Introduction: Psychosocial factors have been implicated as being important in the onset and/or exacerbation of urticaria.

Aim: To examine both personality factors of patients with chronic idiopathic urticaria (CIU) and the correlations between illness duration, severity of itching, urticaria activity score (UAS) and temperament-character dimensions. Material and methods: A total number of $70 \mathrm{CIU}$ patients and 60 healthy individuals were included in the study. The Temperament and Character Inventory (TCI) was administered individually. The relationship between UAS, illness duration and severity of pruritus and $\mathrm{TCl}$ subscales were evaluated.

Results: The CIU group had significantly higher scores of novelty seeking and lower scores of cooperativeness, reward dependence and self-directedness than the control group.

Conclusions: The current study shows that CIU patients have distinctive temperament and character dimensions when compared with the control group. We suggest that evaluation and treatment of CIU should also include psychosomatic approaches in clinical practice.
\end{abstract}

Key words: character, chronic idiopathic urticaria, temperament.

\section{Introduction}

Chronic urticaria (CU) is a polyetiological dermatologic disease [1, 2]. Chronic urticaria can be defined as a daily or almost daily occurrence of temporary and itchy wheals for at least 6 weeks. It remains a major health problem in terms of investigation, aetiology, and management [3]. The etiological reason cannot be found in many cases and the disease is described as chronic idiopathic urticaria (CIU) [4].

Personality traits have been shown to be associated with dermatological disorders [5]. For example, patients with psoriasis, alopecia or urticaria were more hostile and neurotic than people with other dermatological diseases [6]. Psychosocial factors, and personality in particular, play a role in the course and development of CIU as well [7]. Some authors reported that subjects with CIU have significantly interpersonally sensitive, depressive, more hysteric, and suspicious personality traits compared to healthy controls [8]. Until now, few studies have been conducted to investigate the association of personality disorders and psychosomatic disorders with chronic urticaria. However, there is no study that evaluated characteristics of patients with urticaria in terms of temperament and character dimensions.

The dimensional psychological approach to the personality model is developed by Cloninger et al. [9] who defined that personality had two primary components: temperament and character. The character is defined as individuals' relatively objectively, unchanging observed behaviours and subjectively notified inner experiences. Temperament is defined as the

Address for correspondence: Sevil Alan MD, Department of Dermatology and Venereology, Akdeniz University, Tıp Fak, Hastanesi Deri ve Zührevi Hast. ABD, 07070 Antalya, Turkey, phone: +90 5052184284, e-mail: alan_sevil@yahoo.com Received: 6.03.2014, accepted: 5.11.2014. 
aptitude to show an automatic reaction to emotional warnings by being innate structural. It is proclaimed that the components of temperament are genetically independent and show hereditary characteristics by $40 \%$ to $60 \%$, and also, it is proclaimed that the genetic effects in character bases are effective by $10 \%$ to $15 \%$ and the experienced environmental effects by $30 \%$ to $35 \%[9,10]$. According to Cloninger, personality is a result of interaction between environmental and genetic factors [10].

\section{Aim}

The aim of this study is to examine the personality and character features of CIU patients and compare them with healthy controls using the temperament and character inventory $(\mathrm{TCl})$. Our second goal was to evaluate the correlations between temperament and character dimensions with clinical factors such as the illness duration and severity of the pruritus and urticaria activity score (UAS) of CIU patients.

\section{Material and methods}

Seventy patients with CIU and 60 healthy controls, who were referred to the Akdeniz University Dermatology and Venereology outpatient clinic between June 2013 and September 2013 were included in the study. Eligible patients were 18 to 70 years of age, diagnosed with CIU, literate, did not have any systemic or metabolic diseases, and had no dermatological diseases other than CIU. The exclusion criteria were major depression, dementia, mental retardation, cognitive impairment, recurrent suicidal thoughts, psychotic illness, psychiatric drug-use, advanced neurological diseases, and decompensated systemic diseases. Initially, patients with CIU who presented to our dermatology clinic were informed about the study and were asked whether they agreed to participate. After examination in the dermatology clinic, patients diagnosed with CIU and who chose to participate in the study were assessed, and the following demographics were noted: age, gender, education level, and duration of urticaria. Seventy patients who complied with the criteria were included in the study. For the control group, volunteers who were not diagnosed with urticaria or any systemic, metabolic or psychiatric disorder were included. After recording the sociodemographic characteristics of patients and the control group, the TCI was applied.

\section{Ethical considerations}

This study was approved by the ethics committee of the Antalya Education and Research Hospital and conducted according to the ethical standards of the Helsinki Declaration of 2000. All subjects signed written informed consent.

\section{Dermatologic measures}

The urticaria activity score (UAS): The UAS was calculated according to the EAACI/GA2LEN/EDF guidelines [3] and as described by the Maurer group [11]. The UAS was estimated according to the number of wheals and pruritus intensity, on the day of blood sampling, applying the following scheme: no wheals $=0,1-10$ wheals $=1,11-50$ wheals $=2,50$ wheals $=3$ and pruritus intensity: no $=0$, mild $=1$, moderate $=2$, severe $=3$. UAS scores: daily (minimum $=0$; maximum $=6$ ). The UAS was classified as follows: 0-2 (mild), 3-4 (moderate) and 5-6 (severe).

Visual analogue scale (VAS): A visual analogue scale referring to overall urticaria severity during the preceding 2 weeks was completed by the patient at each follow-up appointment. The scale ranged from 0 to 10,0 indicating no disease and 10 indicating very severe urticaria [12].

\section{Psychiatric measures}

Temperament and Character Inventory ( $\mathrm{TCl}$ ): The $\mathrm{TCl}$ has been used extensively in studies relating psychopathology and personality. The TCl was developed by Cloninger et al. [9] and the Turkish version of the $\mathrm{TCl}$ has been validated by Köse et al. [13]. It has been commonly used in different areas of psychiatric and psychological research and practice in the last 10 years. This self-reported scale consists of 240 items with "true" or "false" as the response options; it can be applied to individuals aged 18 years old or older.

The $\mathrm{TCl}$ consists of seven main scales formed by four dimensions of temperament (novelty seeking (NS), harm-avoidance $(H A)$, reward dependence $(R D)$, and persistence $(P))$ and 3 dimensions of character ((self-directedness (SD), cooperativeness (C) and self-transcendence (ST)), along with 24 subscales of these scales: exploratory excitability (NS1), impulsiveness (NS2), extravagance (NS3), disorderliness (NS4); anticipatory worry (HA1), fear of uncertainty (HA2), shyness with strangers (HA3), fatigability (HA4); sentimentality (RD1), openness to warmth (RD2), attachment (RD3); taking responsibility (SD1), intentionality (SD2), resourcefulness (SD3), self-acceptance (SD4), congruent second nature (SD5); social acceptance (C1), empathy (C2), helpfulness (C3), compassion (C4), virtuousness-scrupulousness (C5); self-loss (ST1), people transpersonal identification (ST2), and spiritual acceptance (ST3).

\section{Statistical analysis}

A power analysis demonstrated that 40 patients would be required in each group to detect significant differences in $\mathrm{TCl}$ scores with a power of $80 \%$ and a level of significance of $\alpha=0.05$. Data were computerised using the Statistical Packages for the Social Sciences (SPSS v.18.00; SPSS Inc., Chicago, IL, USA). Both groups were compared in terms of TCI main and sub-scale scores. The Kolmogorov-Smirnov test and Shapiro-Wilk test were 
used to test the normal distribution of the data. As they were normally distributed, the CIU and control (healthy normal) groups were compared with Students $t$-test. Mann-Whitney U-test was used because the data were not compatible with normal distribution. As they were normally distributed, the differences in the TCl scores between the CIU patients and control groups were analysed using an Pearson's correlation test and Spearman's nonparametric correlation test were obtained between the UAS, the illness duration and VAS. A $p$ value $<0.05$ was considered statistically significant.

\section{Results}

The sociodemographic characteristics of patients with CIU and the control group are shown in Table 1. In our study, patients with CIU scored higher on NS (Novelty seeking), NS3 (Extravagance), NS4 (Disorderliness) and spiritual acceptance (ST3) scale/subscales of the TCI than controls $(p<0.05)$. In addition, the scores in HA2 (Fear of uncertainty), C (Cooperativeness), C1 (Social acceptance), C2 (Empathy), C3 (Helpfulness), C4 (Compassion), C5 (Virtuousness scrupulousness), SD (Self-Directedness), SD1 (Taking responsibility), SD2 (Intentionality), SD5 (Congruent second nature), RD1 (Sentimentality), ST2 (People transpersonal identification) scales/subscales were significantly lower in patients with CIU than in controls (Tables 2, 3). There were no significant differences between patients and healthy volunteers with regard to other scales/subscales of the TCI $(p>0.05)$. Additionally, the women with CIU had only a lower score on C2 (Empathy) ( $p=0.007)$. There were no significant differences between men and women with $\mathrm{CIU}$ with regard to other scales/subscales of the TCI $(p>0.05)$.

For all patients, the mean duration of the illness was $60.64 \pm 97.25$ months (6-480 months). Urticaria activity score ranged between 0 and 6 . The mean UAS score was $3.14 \pm 1.60$. Visual analogue scale ranged was $0-10$. The mean VAS score was $7.17 \pm 2.95$. As shown in Table 4, duration of the illness correlated positively with SD (Self-di-

Table 1. Demographic features of patients and control groups

\begin{tabular}{|c|c|c|c|}
\hline Parameter & Patients $(n=70)$ & Controls $(n=60)$ & Value of $p$ \\
\hline Age, mean \pm standard deviation* & $41.56 \pm 11.71$ & $37.80 \pm 11.91$ & 0.111 \\
\hline Gender, $n(\%)^{\star *}$ : & & & 0.123 \\
\hline Female & $52(74.3)$ & $37(61.7)$ & \\
\hline Male & $18(25.7)$ & $23(38.3)$ & \\
\hline Marital status, $n(\%)$ : & & & 0.724 \\
\hline Single & $12(17.1)$ & $16(26.7)$ & \\
\hline Married & 51 (72.9) & $41(68.3)$ & \\
\hline Divorced/widowed & $7(10.0)$ & $3(5)$ & \\
\hline Education, $n(\%)^{\star *}$ : & & & 0.986 \\
\hline Primary school & $36(51.4)$ & $28(56.8)$ & \\
\hline High school & $18(25.7)$ & $16(26.6)$ & \\
\hline University & $16(22.9)$ & $16(26.6)$ & \\
\hline
\end{tabular}

Table 2. Differences between patients and controls with regard to $\mathrm{TCl}$ scales

\begin{tabular}{lccc}
\hline TCl scales & Patients $(n=70)$ & Controls $(n=60)$ & Value of $p$ \\
\hline Novelty seeking (NS) & $22.50 \pm 4.03$ & $20.66 \pm 3.34$ & 0.008 \\
\hline Harm avoidance (HA) & $15.34 \pm 5.17$ & $15.98 \pm 4.23$ & 0.446 \\
\hline Self-directedness (SD) & $15.95 \pm 5.79$ & $18.51 \pm 5.24$ & 0.001 \\
\hline Cooperativeness (C) & $10.80 \pm 4.52$ & $15.70 \pm 4.49$ & $<.001$ \\
\hline Reward dependence (RD) & $8.90 \pm 2.53$ & $9.98 \pm 1.98$ & 0.006 \\
\hline Self-transcendence (ST) & $13.44 \pm 4.777$ & $12.96 \pm 4.23$ & 0.552 \\
\hline Persistence (P) & $2.52 \pm 1.72$ & $2.65 \pm 1.44$ & 0.668 \\
\hline
\end{tabular}


Table 3. Differences between patients and controls with regard to $\mathrm{TCl}$ subscales

\begin{tabular}{|c|c|c|c|}
\hline $\mathrm{TCl}$ subscales & Patients $(n=70)$ & Controls $(n=60)$ & Value of $p$ \\
\hline Exploratory excitability (NS1) & $4.84 \pm 1.62$ & $4.96 \pm 1.38$ & 0.645 \\
\hline Impulsiveness (NS2) & $6.25 \pm 1.33$ & $5.80 \pm 1.64$ & 0.083 \\
\hline Extravagance (NS3) & $4.52 \pm 1.75$ & $3.93 \pm 1.53$ & 0.044 \\
\hline Disorderliness (NS4) & $6.87 \pm 1.76$ & $5.96 \pm 1.80$ & 0.005 \\
\hline Anticipatory worry (HA1) & $4.10 \pm 1.97$ & $4.35 \pm 1.71$ & 0.518 \\
\hline Fear of uncertainty (HA2) & $2.35 \pm 1.48$ & $3.03 \pm 1.50$ & 0.007 \\
\hline Shyness with strangers (HA3) & $3.94 \pm 1.42$ & $3.56 \pm 1.48$ & 0.208 \\
\hline Fatigability (HA4) & $4.95 \pm 2.18$ & $5.03 \pm 1.70$ & 0.706 \\
\hline Taking responsibility (SD1) & $3.75 \pm 1.79$ & $4.41 \pm 1.90$ & 0.046 \\
\hline Intentionality (SD2) & $2.41 \pm 1.53$ & $3.08 \pm 1.66$ & 0.019 \\
\hline Resourcefulness (SD3) & $1.35 \pm 1.16$ & $1.66 \pm 1.32$ & 0.159 \\
\hline Self-acceptance (SD4) & $5.28 \pm 2.39$ & $5.41 \pm 1.89$ & 0.733 \\
\hline Congruent second nature (SD5) & $3.14 \pm 1.71$ & $3.93 \pm 1.91$ & 0.028 \\
\hline Social acceptance (C1) & $1.61 \pm 0.16$ & $2.60 \pm 1.35$ & $<0.001$ \\
\hline Empathy (C2) & $2.00 \pm 1.21$ & $2.50 \pm 1.21$ & 0.016 \\
\hline Helpfulness (C3) & $2.94 \pm 1.06$ & $3.78 \pm 1.30$ & $<0.001$ \\
\hline Compassion (C4) & $1.82 \pm 1.90$ & $3.55 \pm 1.88$ & $<0.001$ \\
\hline Virtuousness-scrupulousness (C5) & $2.42 \pm 1.19$ & $3.26 \pm 1.56$ & 0.001 \\
\hline Sentimentality (RD1) & $1.80 \pm 1.29$ & $2.65 \pm 1.28$ & $<0.001$ \\
\hline Openness to warmth (RD2) & $3.62 \pm 1.46$ & $3.76 \pm 1.28$ & 0.572 \\
\hline Attachment (RD3) & $3.45 \pm 1.34$ & $3.56 \pm 1.38$ & 0.649 \\
\hline Self-loss (ST1) & $4.82 \pm 2.14$ & $4.45 \pm 2.02$ & 0.305 \\
\hline People transpersonal identification (ST2) & $3.25 \pm 1.98$ & $3.95 \pm 1.95$ & 0.048 \\
\hline Spiritual acceptance (ST3) & $5.34 \pm 2.06$ & $4.56 \pm 1.97$ & 0.031 \\
\hline
\end{tabular}

Table 4. Correlations between $\mathrm{TCI}$ scores and duration of disease, itch severity score, and UAS

\begin{tabular}{lcccccc}
\hline Variable & \multicolumn{2}{c}{ Duration of the disease } & Itch severity score (VAS) & \multicolumn{2}{c}{ UAS } \\
\cline { 2 - 7 } & $r$ & $p$ & $r$ & $p$ & $r$ & $p$ \\
\hline Responsibility (SD1) & 0.254 & 0.034 & 0.248 & 0.038 & 0.076 & 0.536 \\
\hline Self-acceptance (SD4) & 0.284 & 0.017 & 0.107 & 0.377 & 0.025 & 0.843 \\
\hline Self-directedness (SD) & 0.245 & 0.041 & 0.133 & 0.272 & 0.062 & 0.617 \\
\hline Self-transcendence (ST) & 0.040 & 0.743 & -0.261 & 0.029 & 0.011 & 0.910 \\
\hline Self-loss (ST1) & 0.039 & 0.753 & -0.235 & 0.049 & 0.097 & 0.305 \\
\hline Reward dependence (RD) & 0.047 & 0.705 & 0.098 & 0.422 & 0.269 & 0.025 \\
\hline Dependence (RD4) & 0.213 & 0.081 & 0.055 & 0.565 & 0.266 & 0.026 \\
\hline
\end{tabular}


rectedness), SD1 (Responsibility), and SD4 (Self-acceptance) subscales. Severity of pruritus correlated negatively with the ST (Self-transcendence) and ST1 (Self-loss) subscales, and positively with the SD1 (Responsibility) subscale. Urticaria activity score correlated positively with RD4 (Dependence) and Reward dependence (RD) subscales.

\section{Discussion}

The aim of this study was to investigate whether the patients with CIU had different personality characteristics than healthy individuals. Patients with CIU were found to score lower on novelty seeking, extravagance and lower on fear of uncertainty, cooperativeness, social acceptance, empathy, helpfulness, compassion, virtuousness-scrupulousness, and self-directedness dimensions of $\mathrm{TCl}$ than healthy subjects.

An association between psychological factors and CIU have been reported [14]. Chronic idiopathic urticaria is often associated with psychiatric symptoms, such as depression and anxiety, and with stress, which may play a role in the genesis of the disease as well as in its evolution [15]. A high prevalence of mental disorders has been reported in patients with urticaria [16]. Staubach et al. [17] have found that $48 \%$ of 111 patients with CU were diagnosed with one or more psychosomatic disorders; most common were anxiety disorders (especially phobias), followed by depressive and somatoform disorders. A similar prevalence rate $(49.4 \%)$ was found in the study by Uguz et al. [8]. In that study [8], the authors have observed that $44.9 \%$ of the patients with CIU had at least one personality disorder and the most common personality disorder was found to be obsessive-compulsive personality disorder (30.3\%). The patients with urticaria were found to be less dominant, more intropunitive, more extrapunitive and more neurotic than the healthy control group [6]. A few studies in the literature have used the NEO-Five Factor Inventory [18] which aims to measure the "Big Five" personality traits: neuroticism, extraversion, openness to experience, agreeableness, and conscientiousness in patients with CIU. People with CIU were found to have a significantly higher level of neuroticism [19] and lower level of extraversion [14] than healthy individuals. However, up to now, no studies have used $\mathrm{TCl}$ to evaluate personality characteristics of patients with CIU.

The personality and character dimensions of patients with dermatological disease is of interest. Kim et al. [20] have shown that the patients with atopic dermatitis were found to score higher on harm avoidance and lower on reward dependence, self-directedness and cooperativeness than the healthy controls. Kılıç et al. [21] have investigated 105 patients with psoriasis and found that the patients had significantly higher scores of harm avoidance and lower scores of being self-directedness than the control group. Reward dependence, persistence, fear of uncertainty, harm avoidance, self-directedness, cooperativeness and self-transcendence scores were found to be significantly higher in hyperhidrosis patients when compared with healthy controls [22]. In our study, patients with CIU were found to score higher on novelty seeking and extravagance dimensions of $\mathrm{TCl}$ than healthy subjects. Novelty seeking and extravagance are human personality traits characterized by impulsive, exploratory, or sensation-seeking behaviour. We also found that CIU patients had lower scores on fear of uncertainty dimension and fear of uncertainty is the central psychological motivation underlying conservatism. Moreover, patients with CIU had lower scores on cooperativeness, social acceptance, empathy, helpfulness, compassion, and virtuousness-scrupulousness dimensions. These findings may reveal that patients with CIU have a deficit in social interactions.

Personality traits are shown to play a role in the development and progression of medical problems because they have been shown to contribute to the development and progression of health problems [23]. Cloninger's model of personality gives the possibility to establish a connection between functioning of brain systems of interconnected neurons governing behavioural activation, behavioural inhibition, and behavioural maintenance [24]. For example, the temperament dimension of harm avoidance is suggested to indicate central serotonergic turnover [25]. An inverse relationship was found between harm avoidance and serotonin and a positive relationship between self-directedness and serotonin [26]. Moreover, dopamine was shown to be related with novelty seeking [27]. Some neurotransmitters are speculated to play an important role in specific types of urticaria [28]. Two types of urticaria are described according to this view: 1) Adrenergic urticaria, a rare form of stress-induced physical urticaria, caused by various triggers, including emotional upset, coffee, and chocolate, during which serum catecholamines and IgE are elevated, whereas histamine and serotonin levels remain within normal limits [29], 2) Cholinergic urticaria, which is associated with nicotine, acetylcholine, or methacholine [30]. In this respect, neurotransmitter alterations may explain the relationship between personality dimensions and CIU. In this study we found that duration of the disease, urticar$\mathrm{ia}$, and pruritus severity and frequency of attacks weak correlated with certain personality traits. Thus our results may contribute to the literature revealing that psychological factors play an important role in the attacks and frequency of exacerbations of urticaria. We believe this study will provide a contribution to further studies in understanding the role of personality characteristics in CIU.

\section{Conclusions}

The current study shows that CIU patients have distinctive temperament and character dimensions when 
compared with the control group. We suggest that evaluation and treatment of CIU should also include psychosomatic approaches in clinical practice.

\section{Conflict of interest}

The authors declare no conflict of interest.

\section{References}

1. Kaplan AP. Chronic urticaria: pathogenesis and treatment. J Allergy Clin Immunol 2004; 114: 465-74.

2. Brzewski PŁ, Spałkowska M, Podbielska M, et al. The role of focal infections in the pathogenesis of psoriasis and chronic urticaria. Postep Derm Alergol 2013; 30: 77-84.

3. Zuberbier T, Asero R, Bindslev-Jensen C, et al. EAACl/ GA2LEN/EDF/WAO guideline: definition, classification and diagnosis of urticaria. Allergy 2009; 64: 1417-26.

4. Kaplan AP. Clinical practice. Chronic urticaria and angioedema. N Engl J Med 2002; 346: 175-9.

5. Bahmer JA, Kuhl J, Bahmer FA. How do personality systems interact in patients with psoriasis, atopic dermatitis and urticaria? Acta Derm Venereol 2007; 87: 317-24.

6. Lyketsos GC, Stratogos GC, Tawil G, et al. Hostile personality characteristics, dysthymic states and neurotic symptoms in urticaria, psoriasis and alopecia. Psychother Psychosom 1985; 44: 122-31.

7. Pasaoglu G, Bavbek S, Tugcu H, et al. Psychological status of patients with chronic urticaria. J Dermatol 2006; 33: 765-71.

8. Uguz F, Engin B, Yilmaz E. Axis I and Axis II diagnoses in patients with chronic idiopathic urticaria. J Psychosom Res 2008; 64: 225-9.

9. Cloninger CR, Svrakic DM, Przybeck TR. A psychobiological model of temperament and character. Arch Gen Psychiatry 1993; 50: 975-90.

10. Cloninger CR. Temperament and character. Curr Opin Neurobiol 1994; 4: 266-73.

11. Altrichter S, Boodstein N, Maurer M. Matrix metalloproteinase-9: a novel biomarker for monitoring disease activi activity in patients with chronic urticaria patients? Allergy 2009; 64: 652-6.

12. Ucmak D, Akkurt M, Toprak G, et al. Determination of dermatology life quality index, and serum C-reactive protein and plasma interleukin- 6 levels in patients with chronic urticaria. Postep Derm Alergol 2013; 30: 146-51.

13. Köse S, Sayar K, Ak I, et al. Turkish version of the Temperament and Character Inventory (TCI): reliability, validity, and factorial structure. Klin Psikofarmakol B 2004; 14: 107-31.

14. Chung MC, Symons C, Gilliam J, Kaminski ER. The relationship between posttraumatic stress disorder, psychiatric comorbidity, and personality traits among patients with chronic idiopathic urticaria. Compr Psychiatry 2010; 51: 55-63.

15. Berrino AM, Voltolini S, Fiaschi D, et al. Chronic urticaria: importance of a medical-psychological approach. Eur Ann Allergy Clin Immun 2006; 38: 149-52.

16. Hashiro M, Okumura M. Anxiety, depression, psychosomatic symptoms and autonomic nervous function in patients with chronic urticaria. J Dermatol Sci 1994; 8: 129-35.

17. Staubach P, Dechene M, Metz M, et al. High prevalence of mental disorders and emotional distress in patients with chronic spontaneous urticaria. Acta Derm Venereol 2011; 91: 557-61.
18. Costa Jr PT, McCrae RR. Revised NEO Personality Inventory (NEO-PI-R) and NEO Five-Factor Inventory (NEO-FFI) professional manual. Psychological Assessment Resources, Odessa, FL 1992.

19. Ma LH, Tang LY, Luo GY, et al. A survey of psychosocial factors of psychosomatic diseases. Chin J Clin Psychol 2002; 10: 266-9.

20. Kim TS, Pae CU, Jeong JT, et al. Temperament and character dimensions in patients with atopic dermatitis. J Dermatol 2006; 33: 10-5.

21. Kılıç A, Güleç MY, Gül Ü, Güleç H. Temperament and character profile of patients with psoriasis. JEADV 2008; 22: 537-42.

22. Karaca S, Emul M, Kulac M, et al. Temperament and character profile in patients with essential hyperhidrosis. Dermatology 2007; 214: 240-45.

23. Friedman HS, Boothkewley S. The Disease-prone personality - a meta-analytic view of the construct. Am Psychologist 1987; 42: 539-55.

24. Cloninger CR. A systematic method for clinical description and classification of personality variants. Arch General Psychiatry 1987; 44: 573-88.

25. Allgulander C, Cloninger CR, Przybeck TR, Brandt L. Temperament and character improvement with paroxetine treatment in patients with GAD. Psychopharmacol Bull 1998; 34: 165-6.

26. Peirson AR, Heuchert JW, Thomala L, et al. Relationship between serotonin and the temperament and character inventory. Psychiatry Res 1999; 89: 29-37.

27. Tsuchimine S, Yasui-Furukori N, Kaneda A, et al. Minor genetic variants of the dopamine D4 receptor (DRD4) polymorphism are associated with novelty seeking in healthy Japanese subjects. Prog Neuropsychopharmacol Biol Psychiatry 2009; 33: 1232-5.

28. Maerens-Tchokokam B, Vigan M, Breuillard F, et al. Guess what! Adrenergic urticaria. Eur J Dermatol 1999; 9: 137-8.

29. Shelley WB, Shelley ED. Adrenergic urticaria: a new form of stress-induced hives. Lancet 1985; 8643: 1031-3.

30. Deacock SJ. An approach to the patient with urticaria. Clin Exp Immunol 2008; 153: 151-61. 